\title{
EDITORIAL
}

\section{Tracing circulations The case of the Mercator-Hondius Atlas (1613)}

$\mathrm{T}$

he subject of this thematic issue of Approaching Religion is an early seventeenth-century edition of Gerardus Mercator's Atlas sive cosmographicae meditationes de fabrica mundi et fabricati figura. The book is housed in the library of the Donner Institute, near the River Aura, in Turku ( $\AA$ bo), Finland. The edition is commonly known as the Mercator-Hondius Atlas due to the decisive role of the engraver and map-maker Jodocus Hondius in completing and transforming the atlas into a commercial success. The atlas was first published by Mercator's sons in 1595, the year after Mercator's death. Around 1604 Mercator's grandson sold the copperplates to publisher Cornelis Claesz. and engraver Jodocus Hondius(van der Krogt 1997: 31-9).
The EDITION OF 1613 is not considered to be a special case among the various printings of the atlas. It was published after the death of Hondius in February 1612 by his widow and sons. This edition marked the end of an era, as Hondius' role in extending and completing the earlier editions had been decisive. The different editions of the Mercator-Hondius Atlas were representations of the known world. They reflected the expansion of Europe during a period of widening geographical horizons, but above all they spatialized knowledge of the world by presenting it in the form of a set of maps and texts that were bound together to form a valuable folio book.

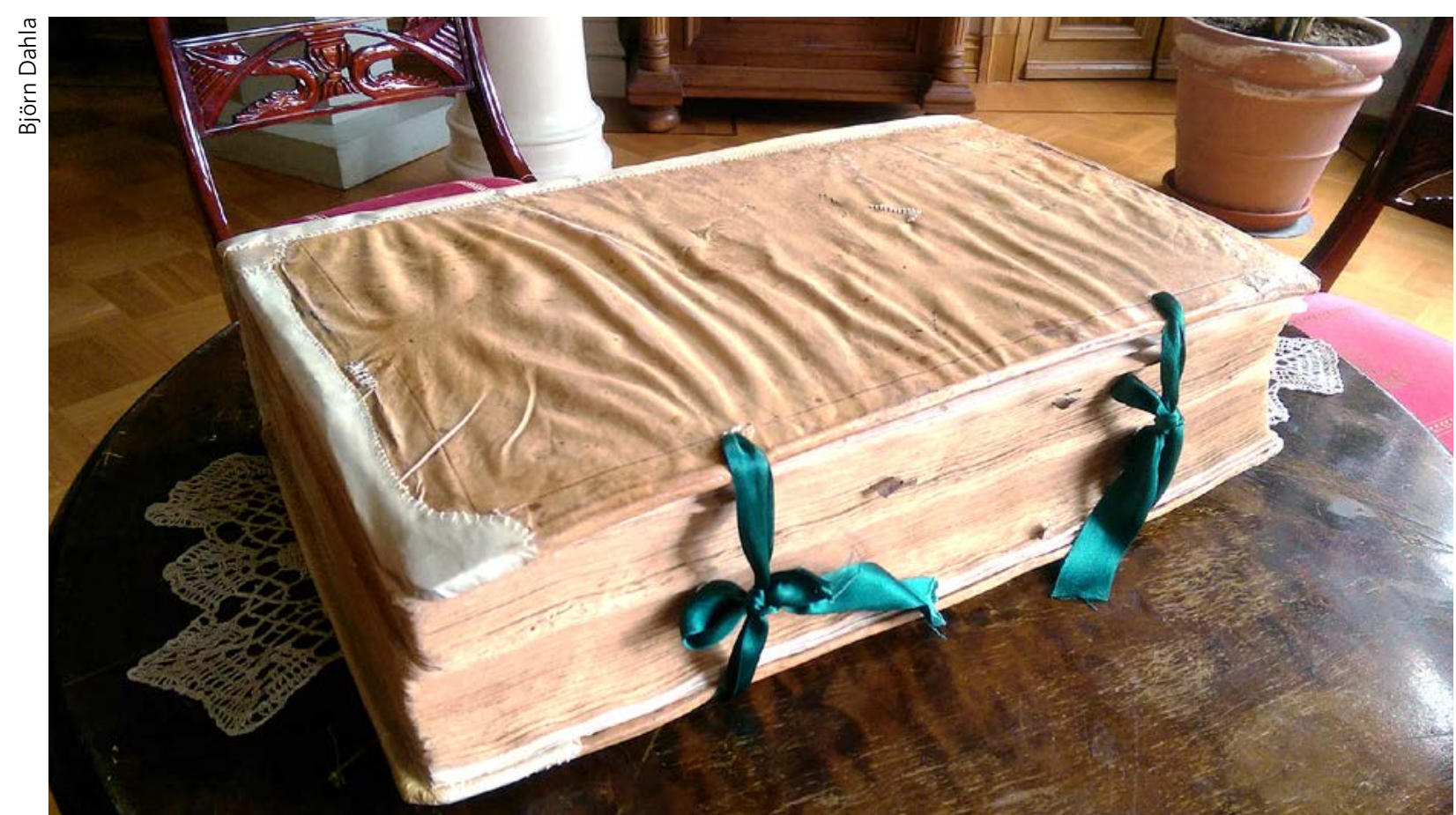

The Turku copy of the Mercator-Hondius Atlas at the Donner Institute. 
The histories of cartography have not emphasised the importance of Hondius' last edition but it remains as a representative of Dutch map-making of the period, when the intellectual and religious endeavours that were present in Mercator's studies yielded to the commercial aspirations of the seventeenth-century publishers. The atlas was an item of consumption: it was a heavy book that was sold, bought and borrowed, and many readers left the marks of their use on it. Consequently, all the copies have become unique witnesses of the circulation, reception and use of the atlases in the seventeenth century and later.

The edition of 1613 modestly commemorated Hondius, whose life and work did not seem to have any particular relevance to the progress of cartography, unlike Mercator's. The studies of Hondius have often regarded him as a representative of cartography which followed the golden age of Mercator and Abraham Ortelius. The third volume of the seminal History of Cartography series discusses Hondius among the other Amsterdam-based publishers at the turn of the sixteenth and seventeenth centuries, while the studies of Mercator's atlas usually dismiss its later editions (Koeman et al. 1997). For example, an influential collection of articles inspired the 4ooth anniversary of the cartographer's death - Gerhard Mercator, Europa und die Welt (1994) is dedicated to Mercator's own atlas and to his oeuvre in general, even though it is nowadays known mostly through the posthumous editions. The need to concentrate on Mercator's person and on his achievements has produced many fine articles but simultaneously it perpetuates the idea of the great men, great ideas or influential periods, which revolutionised the history of science.

In fact, from the viewpoint of, for example, the history of globalization, Jodocus Hondius is as fascinating a cartographer as Mercator. It was Hondius who published an atlas which covered all the known parts of the world in 1606. He succeeded in this by adding his own maps as well as the works of other cartographers to the maps of Mercator. Hondius was obviously very skilful in utilising maps, texts and other forms of geographical information that were available in the Western Europe of his time. The Mercator-Hondius Atlas should thus be considered as a product of the ideas and materials that circulated in the European or Dutch cartographical community and not as the work of Mercator or Hondius alone. Consequently, scrutinizing the ideas and mater- ials that produced this kind of major cartographical enterprise is of the utmost value when writing the history of the different editions of the atlas.

\section{Four approaches to the Mercator-Hondius Atlas}

This issue of Approaching Religion consists of four research articles which illustrate how the MercatorHondius Atlas as an historical object facilitates interdisciplinary enquiries. The research articles are accompanied by an introduction by Tore Ahlbäck, who was the director of Åbo Akademi University Library at the time when the atlas was acquired. Ahlbäck's reminiscences clarify the latest stages of the reception of the atlas.

Mari-Liisa Varila and Steven Van Impe have contributed an article entitled 'The biography of a book: the Turku copy of the 1613 Mercator-Hondius Atlas'. Unlike most historians of biblio-cartography, Varila and Van Impe do not analyse an edition or a copy that is considered unusual or exceptional. Instead, they make a copy-specific study of one of the MercatorHondius atlases that were published in 1613. Even though the copy held in Turku is not a special case, it is unique. Like every printed book, the atlas has travelled from hand to hand and has been affected by its owners. The binding and insertions made by the book-owners, therefore, provide source material for research which is just as valuable as the intellectual background of the map-makers or the economic conditions that influenced their work. Varila and Van Impe pay special attention to the marks of provenance that the atlas contains. The Mercator-Hondius Atlas was utilised for various purposes and its reception and use should be regarded as being as important as its production.

While Varila's and Van Impe's analysis is concerned with the atlas as a physical object, Otto Latva and Johanna Skurnik engage with it by examining the contents of the maps. The different choices made by the cartographers when authoring their maps are analysed as examples of the processes of knowledge production. An examination of how the world is represented on maps by means of textual descriptions and illustrations is of importance when aiming to comprehend what kind of information the atlas communicated to its users. At the core of the processes of knowledge production is the idea of circulation - the circulation of practices, techniques, materials and information. Early modern cartographers 
constructed their maps using different kinds of sources, ranging from the texts deriving from the ancient authorities to the latest accounts by travellers to foreign seas and lands. Furthermore, they used maps prepared by their colleagues, borrowing their data or straightforwardly printing maps based on their plates.

Texts are equally as important in the atlas as are the maps. Gerardus Mercator had planned to compile his atlas as a description of the complete order of God's creation. To achieve this, he needed words, which were more adaptable than maps in representing the universal order that Mercator had presupposed. In addition to cosmographical meditations the atlas maps were accompanied by on verso texts. These texts explained and contextualized the maps, describing such unobservable phenomena as the cartographer was unable to draw. The editions prepared by Hondius utilised Mercator's text but also incorporated new texts by Petrus Montanus, a learned Dutch writer.

The characteristics of the texts are perused from two distinct perspectives by Aleksi Mäkilähde and Janne Tunturi. In his article, Mäkilähde tackles the multilingual nature of the atlas and examines the different languages used in the on verso texts and on the maps. Mäkilähde approaches the atlas from a linguistic point of view and analyses code-switching and language alternation in the descriptive texts and the texts on the maps. Mäkilähde analyses how the dominant role of Latin is reflected in the on verso texts and how different languages are used to structure the maps. Mäkilähde's analysis makes explicit that both in the texts and the maps code-switching and language alternation are multifaceted and their patterns are not easily trackable. The multilingual nature of the atlas highlights how materials circulating in many languages were adapted and copied when compiling the maps and texts for the atlas.

Furthermore, the texts by Montanus communicate valuable information about the worldviews of the erudite early seventeenth-century Dutch. In his article, Janne Tunturi studies the different temporal dimensions of the atlas by analysing the representations of the past in the maps and the texts. Tunturi's analysis demonstrates that both Jodocus Hondius and Petrus Montanus were hesitant about making comments on the new geographical knowledge resulting from recent expeditions. Rather, Hondius' maps emphasised the expeditions of Columbus,
Björn Dahla

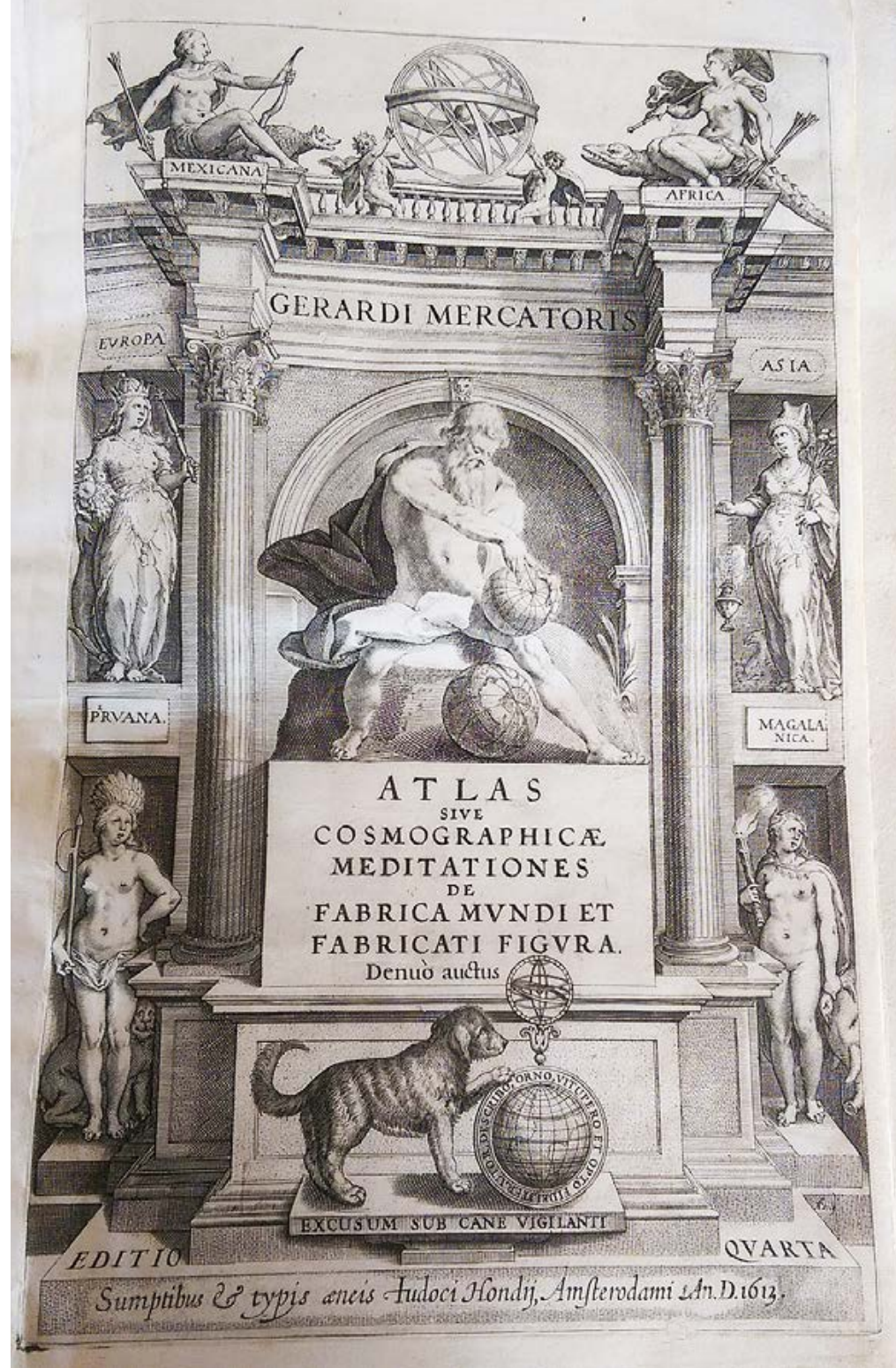

The title page of the the Mercator-Hondius Atlas with allegorical figures representing the known world.

while the information Petrus Montanus referred to was also mostly from the early sixteenth century. In general, Montanus' texts commented more lavishly on the past, especially on biblical, ancient and medieval history, than on the maps in the atlas.

These four approaches reflect the current state of the history of cartography, which has undergone profound changes over the past few decades. The focus of research has shifted from examinations of their internal characteristics and bibliographical investigations to examining maps as historical and contextdependent representations of various phenomena. Starting from the 1980s, scholars, led by the historian 
John Brian Harley, have directed attention to understanding maps as socio-cultural products, the meanings of which are not given (Harley 1988). More recently, researchers have increasingly widened the scope of research to explore maps as the outcomes of mapping processes. For example, Matthew Edney (2014) has urged scholars to engage in 'processual' map history: to research and write a history of maps, mapping and cartography that takes into account 'the many processes by which maps have been produced, circulated and consumed'. Put concretely, research in map history should comprise of studying maps as physical and graphic objects, the techniques and practices of map-making and tracing the circulation and consumption of maps.

Edney's urge to direct attention towards map use connects to larger questions concerning the role of maps as a representational category. Indeed, enormous attention has been devoted to research on how maps not only represent the world, but also produce it. The imaginative interpretations of Tom Conley and Christian Jacob, for example, have even considered cartography as 'location machinery' and a creator of differences between map and territory. They have thus emphasised cartography as an act which creates space in a negotiation with geographical reality (Conley 2007, 2011; Jacob 2006). Depending on the interpretation, this view can emphasise either material conditions or human initiative and imagination in cartography.

Consequently, examinations of how maps 'do diverse work in the world' have highlighted the importance of analysing not only what is selected to be represented in the maps, but also how maps are used. For example, Rob Kitchin, Justin Gleeson and Martin Dodge (2012: 481) argue that epistemologically speaking, maps 'come into being through practices' and they should be understood as mappings that are solutions to relational problems. Kitchin et al. (2012: 481, see also della Dora 2009) emphasise, therefore, that attention should rather be directed to analysing the ontogenesis - the processes leading to the development of maps - than the ontology of maps and cartography. This leads to an examination of how 'mappings unfold' through discursive events and material sites in conjunction with other modes of communication.

Examining map history as processual has much in common with approaches developed particularly within the field of book history and the history of science. Both of these fields of study have made explicit the usefulness of considering the materiality of the sources used. Applied to the study of map history and the history of cartography, an analysis of the maps, the texts and the atlas itself as physical objects, with their particular details, were created and used undoubtedly offers interesting insights into wider epistemological questions. Consequently, researching the processes leading to the construction of maps, atlases, globes and other related materials sheds light on the more general questions of producing knowledge of the world, transforming that knowledge into material objects and communicating it to different audiences. All of these processes can be efficiently comprehended through the theoretical concept of circulation. As the articles in this issue demonstrate, alongside the actual circulations of the atlases produced, it is important to consider the circulations of information and different types of source materials used by the authors of the texts and the maps.

\section{The Mercator-Hondius Atlas as an exemplary case}

By perusing the edition of the atlas stored here from different perspectives the articles of this issue have directed attention on to one particular object relevant to the history of cartography. This particular copy of the Mercator-Hondius Atlas was chosen because of its location at the Donner Institute in Turku: the city where most of the researchers participating in this project reside. The limitations of the copy-specific approach are obvious; for example an analysis of the circulation, reception and use of one copy remains narrow. Nevertheless, concentrating on a single copy of the atlas, even without any special antiquarian value, has its benefits too.

First of all, the study of one object increases awareness of its details, as Varila and Van Impe's article indicates. Secondly, it highlights the interdisciplinary nature of the history of cartography, as the various approaches convincingly show that the same object contains many layers of culturally constructed meanings. The articles in this issue have been influenced by current interdisciplinary approaches in the history of cartography. They recognize the cartobibliographical tradition, but consider the impact and utilise the theories and methods of other fields of study as well. The writers are philologists and historians to whom the study of fragments and singular sources is not exceptional. 
The contributions in this volume have tentatively studied the atlas as an exemplary case, a physical object demonstrating the circulations of knowledge, techniques, and practices which were required to construct it. The present location of the atlas as well as our research on it are part of the same process. The 'Turku copy' directs attention to local, national and global preconditions for the circulation as well. The copy studied in this issue was acquired by Åbo Akademi University Library in 2008. It is not the famous first edition of the Atlas sive cosmographicae that can be found, for instance, at the University Library of Helsinki, within the famous A. E. Nordenskiöld Map Collection. That collection was bequeathed to the only academic library in the Grand Duchy of Finland during the years of the national revival (Pietilä-Ventelä 2013). Instead, it is a copy that the only Swedish-speaking university in Finland succeeded in buying just before the global financial crisis. Now the visitors to the Donner Institute can find surprisingly detailed information on early modern Finland in its maps and texts. As such, the 'Turku copy' of the Mercator-Hondius Atlas is an excellent example of the atlas as a product of the multifaceted processes of constructing knowledge of the world which aims at communicating such knowledge to various audiences.

\section{Johanna Skurnik and Janne Tunturi} Guest editors

\section{Bibliography}

Conley, Tom, 2007. Cartographic Cinema (Minneapolis, University of Minnesota Press)

-2011. An Errant Eye: Poetry and Topography in Early Modern France (Minneapolis, University of Minnesota Press)

della Dora, Veronica, 2009. 'Performative atlases: memory, materiality, and (co-)authorship', Cartographica, 44(4), pp. 240-55

Edney, Matthew H., 2014. 'Academic cartography, internal map history, and the critical study of mapping processes', Imago Mundi, 66, pp. 83-106

Harley, John Brian, 1988. 'Maps, knowledge and power' in The Iconography of Landscape: Essays on the Symbolic Representation, Design and Use of Past Environments, eds. Denis Cosgrove and Stephen Daniels (Cambridge University Press), pp. 277-312

Jacob, Christian, 2006. The Sovereign Map: Theoretical Approaches in Cartography throughout History (The University of Chicago Press)

Kitchin, Rob, Justin Gleeson, and Martin Dodge, 2012. 'Unfolding mapping practices: a new epistemology for cartography', Transactions of the Institute for British Geographers, 38, pp. 480-96

Koeman, Cornelis, Günter Schilder, Marco van Egmond, and Peter van der Krogt, 2007. 'Commercial cartography and map production in the Low Countries, 1500 - ca. 1672' in The History of Cartography, vol. 3, Cartography in the European Renaissance, part 2 (Chicago University Press), pp. 1296-1383

Pietilä-Ventelä, Anna-Maija, 2013. 'An appreciation of Adolf Erik Nordenskiöld and his remarkable collection' in The Emerging World: Map Treasures from the A. E. Nordenskiöld Collection, eds. Tapio Markkanen, Leena Miekkavaara and Anna-Maija Pietilä-Ventelä (Helsinki, SKS)

Van der Krogt, Peter, 1997. 'The folio atlases published by Gerard Mercator, Jodocus Hondius, Henricus Hondius, Johannes Janssonius and their successors' in Koeman's Atlantes Neerlandici, vol. 1 (Leiden, Brill) 